three-layered structures, are possible, so Fig. 2 focuses attention on only a few. Electron microscopy of frozen-hydrated crystals may eliminate some of these.

The great merit of the experiments of Clarke et al.' is that not only do they provide strong evidence for a gate which is integral with the channel, but they also point the way to further progress. One of the problems with site-directed mutagenesis is the choice of residues that might generate interesting mutants. The success rate should now be greatly increased by using the critical sites identified by Clarke et al. as starting points for exploring the surfaces of helices that might line the channel. The results so far have been obtained with only a few micrograms of each mutant. Purification of larger amounts would allow our extensive knowledge of the kinetics of the transport process to be more fully exploited.

The results are relevant to other P-type ion pumps. Although these show 30-50 per cent sequence identity in the cytoplasmic region ${ }^{8}$, their transmembrane segments have little more than their hydrophobicity in common. Only the $\mathrm{Na}^{+} /$ $\mathrm{K}^{+}$and $\mathrm{H}^{+} / \mathrm{K}^{+}$pumps can be unequivoc- ally aligned. It is therefore particularly striking that the general pattern of the critical polar groups identified by Clarke et al.' persists in all but the bacterial pumps. The variety of ion-transport processes that can be coupled to a homologous ATP-driven phosphorylation mechanism is an intriguing feature of these pumps. The new observations bring this puzzle into sharper focus. It may be resolvable by analogous studies of mutants of other members of the family ${ }^{9}$.

N. Michael Green is in the Laboratory of Protein Structure, National Institute for Medical Research, Mill Hill, London NW7 IAA, UK.

1. Clarke, D.M., Loo, T.W., Inesi, G. \& MacLennan, D.H Nature 339, 476-478 (1989).

2. Brandl, C.J., Green, N.M., Korczak, B. \& MacLennan, D.H. Cell 44. 597-607 (1986).

3. Clarke. D.M. et al. J. biol. Chem. (in the press).

4. Tanford. C. Proc. natn. Acad. Sci. U.S.A. 79, 2882-2884 (1982).

5. Edmonds, D.T. in Biological Membranes Vol. 5 (ed. Chapman, D.) 350-387 (Academic, London, 1984).

6. Green, N.M., Taylor, W.R., Brandl, C.J., Korczak, B. \& MacLennan, D.H. in Caicium and the Cell Ciba Fon Symp. 122, 93-113 (1986).

7. Taylor, K.A., Dux, L. \& Martonosi, A. J. molec. Biol. 187 417-427 (1986)

8. Serrano, R. Biochim biophys. Acta 947, 1-28 (1988).

9. Portillo, F. \& Serrano, R. EMBO J. 7, 1793-1798 (1988), VIROLOGY

\title{
Leukaemia virus receptor
}

\author{
Robin A. Weiss
}

FOR 25 years, researchers have tried without much success to identify the cell surface receptors that determine the binding and entry into cells of C-type leukaemia and sarcoma viruses. In the 19 May issue of

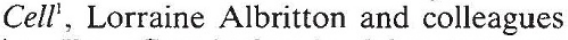
in Jim Cunningham's laboratory at Harvard Medical School describe the cloning and characterization of the receptor for the murine ecotropic leukaemia virus (MuLV-E). The only other retrovirus receptor identified to date is the CD4 antigen recognized by human and simian immunodeficiency viruses ${ }^{2-6}$.

MuLV genomes of laboratory mice are transmitted through the germ line as proviruses integrated in the chromosomal DNA. After activation to infectious form, some strains of MuLV infect mouse cells whereas others can only infect cells of foreign species. Jay Levy ${ }^{7}$ coined the terms 'ecotropic' (MuLV-E) and 'xenotropic' (MuLV-X) to denote this difference in viral host range. Some wild mice also harbour 'amphotropic' virus (MuLVA) that infects both murine and foreign cells. Susceptibility to infection is determined by the presence of cell surface receptors specific to the gp70 envelope antigens of MuLV-E, MuLV-X and MuLV-A, respectively. Albritton et al. ${ }^{\mathrm{t}}$ used this fact to clone the mouse receptor gene by transfecting murine DNA into the

human EJ bladder carcinoma cell line, together with the gpt gene, thus allowing the selection of cells in medium containing mycophenolic acid. The surviving cells were then exposed to a recombinant mouse sarcoma virus (MSV-NEO) genome carrying the G418 drug-resistance marker in an ecotropic envelope. Only those human cells transfected with and expressing the ecotropic receptor gene should be infectible with the MSV-ENO genome and thus become G418-resistant.

Of about 20,000 gpt-resistant human cell clones, Albritton et al. recovered 12 G418 resistant colonies, only one of which was susceptible to secondary infection with another ecotropic vector carrying methotrexate resistance. They derived secondary transfectant EJ cells from this susceptible clone, eventually cloning the receptor gene from one of these secondary transfectants using highly repetitive murine DNA sequences as tags. Complementary DNA libraries were then used to identify a complete receptor gene transcript, and transfection of the cDNA clone also conferred susceptibility to MuLV-E on human cells. The cDNA for the receptor contains an open reading frame which encodes a protein of 622 amino acids and of relative molecular mass 67,000 . The putative protein is extremely hydrophobic containing up to 14 membrane-spanning domains. This protein is not related to any previously deposited in gene and protein sequence data banks.

This study opens the way for a detailed analysis of the MuLV-E receptor and investigation as to whether receptors for other C-type retroviruses belong to the same family. The normal function of this newly discovered membrane protein will also be of interest. With its multiple hydrophobic domains resembling transmembrane sequences, it may act as a transporter molecule ${ }^{8}$.

Retrovirus receptor genes were first defined in chickens using classical mendelian segregation of virus susceptibility ${ }^{9-11}$. Later, somatic-cell hybrids between susceptible and resistant species were used to locate the MuLV-E receptor gene to murine chromosome 5 (refs 12,13 ). It is satisfying that the newly cloned gene resides on this chromosome'. Somatic hybrids have also been used to locate the receptor gene for human $\mathrm{T}$-cell leukaemia viruses types I and II to human chromosome 17 (ref. 14), and several groups are now trying to identify this receptor through expression cloning systems.

It is interesting that the recently cloned receptors for poliovirus ${ }^{15}$ and rhinovirus ${ }^{16,17}$ (ICAM-1) belong to the immunoglobulin superfamily, like the HIV receptor (CD4). The Epstein-Barr virus receptor is the C3D complement receptor ${ }^{18}$, another cell surface molecule with immunological functions. The MuLV-E receptor clearly is an entirely different kind of molecule. Some retroviruses may use more than one receptor. McGrath and Weissman ${ }^{19}$ postulated that thymotropic MuLV strains may recognize $\mathrm{T}$-cell receptors, and we recently demonstrated CD4-independent infection of glial and muscle cells by $\mathrm{HIV}^{20}$. Given the great diversity of retroviruses with respect to host range and cellular tropism, there may be new kinds of receptor awaiting discovery.

Robin A. Weiss is at the Chester Beatty Laboratories of the Institute of Cancer Research, Fulham Road, London SW3 6JB, UK.

1. Albritton, L.M., Tseng, L., Scadden, D. \& Cunningham, J.M. Cel/57, 659-666 (1989).

2. Dalgleish, A.G. et al. Nature 312, 763-767 (1984)

3. Klatzmann, D. et al. Nature 312, 767-768 (1984).

4. McDougal, J.S. et al. Science 231, 382-385 (1986)

5. Maddon, P.J. et al. Cell 47, 333-348 (1986).

6. Sattentau, Q.J. et al. AIDS 2, 101-105 (1988)

7. Levy, J.A. Science 182, 1151-1153 (1973)

8. Lodish, H.F. Trends biochem. Sci. 13, 332-334 (1988).

9. Payne, L.N. \& Biggs, P.M. Virology 24, 610-616 (1964)

10. Rubin, H. Virology 26, 270-276 (1965)

11. Vogt, P.K. \& Ishizaki, R. Virology 26, 664-672 (1965)

12. Ruddle, N.H. et al. J. exp. Med. 148, 451-465 (1978).

13. Oie, H.K. et al. Nature 274, 60-62 (1978).

13. Oie, H.K. et al. Nature 274. 60-62 (1978).
14. Sommerfelt. M.A. et al. Science 242, 1557-1559 (1988).

15. Mendeisohn, C.L., Wimmer, E. \& Racaniello, V.R. Cell 56, 855-865 (1989)

16. Greve. J.M. et al. Cel/ 56, 839-847 (1989).

17. Staunton, D.E. et al. Cel/56, 849-853 (1989)

18. Fingeroth, J.D. et al, Proc. natn. Acad. Sci. U.S.A. 81 , 4510-4514 (1984).

19. McGrath, M.S. \& Weissman, I.L. Cell 17, 65-75 (1979). 20. Clapham, P.R. et al. Nature 337, 368-370 (1989). 